\title{
[12]
}

\section{Performance and the Cultural Construction of Reality: A New Guinea Example}

\author{
Edward L. Schieffelin
}

It is not an uncommon experience for an ethnographer toward the end of the second year of fieldwork to realize suddenly that some issue or activity, long since thought to be thoroughly understood and laid to rest in his or her fieldnotes, had an unsuspected dimension that required its significance to be entirely reexamined. For me, the realization arrived while I was writing my fieldnotes the morning after attending a late-night spirit séance in a Kaluli longhouse. I had attended many of these performances before. The moment in question was not an unusual one for this kind of thing: the medium —or rather the voice of the spirit-had come up without identifying itself and simply begun to sing. Singing at first alone, the tiny voice was eventually answered by a chorus of the men gathered around, filling the

This chapter first appeared in American Ethnologist 12:4, November 1985, and is reprinted by permission of the American Anthropological Association. Many people have contributed to the richness of this paper. I would like especially to thank Steven Feld, Sherry Ortner, Martha MacIntyre, Debra Battaglia, Bruce Knauft, Roy Wagner, Lee Schlesinger, Bill Murphy, and DeVerne Smith for many useful comments and criticisms. My research was undertaken in Papua New Guinea in 1966-68 and 197577 with grants from the National Institutes of Mental Health and the National Science Foundation. Assistance in administering these grants was provided by the Institute for the Study of Human Issues, and the Research Institute for the Study of Man. Their help is gratefully acknowledged here. 
darkness around the medium with resonance and human presence. The song was a Gisaro song (Schieffelin 1976; Feld 1982) and, as is usual for this genre, concerned brooks and gardens, house sites and sago places in the nearby tropical forest. The places named began to trace out a route or track (tok) from the distant longhouse of Kokonesi to the community of Nagibeden where the séance was being held. As the places named seemed to move closer and closer, describing fishing sites and stands of arrow-making cane, cries of "alas!" and whistles of sympathy and dismay escaped from listeners in the darkness; suddenly, with loud wails of grief, a man beside me began to weep. The significance of the song and the people's reactions to it were all familiar to me. The spirit was that of a small boy of the Nagibeden community who had died while visiting Kokonesi longhouse the year before. The path traced out by the song was the track followed by his relatives as they brought his body back to Nagibeden for the funeral. The man weeping in anguish beside me was the boy's own father.

As I was writing about this in my fieldnotes, I was aware that my explanation of what was happening was correct as far as it went, but I realized that this was no professionally detached description that I was writing down: in order to convey and account for the deeply moving and compelling quality of the performance, the rapt engagement of the audience, and my own enthrallment with what was happening, what I was writing was not so much a description of the events as an attempt to evoke the experience.

It was not just that the places named in the song outlined a path that recalled a tragic event still very painful to those who were involved-it was also the way the names engendered suspense as the path, at first unknown, gradually began to become clear; it was the pain engendered as the places named and hence, in imagination, the body of the child, drew nearer and nearer. It was not what the spirit said that distressed the father so much as the presence of his voice in the darkness. These things could not be conveyed simply by recounting them in a straightforward descriptive manner; the events had to be interpreted by understanding how they evoked the audience's feelings (and my own), if they were to make adequate sense at all. The issue here is a larger one than simply providing an accurate ethnographic account of the significance of a dramatic cultural performance. It involves the more intriguing question of the relation between the nondiscursive (dramaturgical and rhetorical) levels of ritual performances and their meaning. 


\section{Edward L. Schieffelin}

Most anthropological studies of ritual in recent years have addressed the problem of what rituals mean and how they work by focusing on the symbolic meanings embodied in the structure and content of ritual symbols themselves, viewing ritual acts and statements as a kind of coded communication, a cultural text. The analysis of the ritual then tends to take the form of a textual analysis, and the main weight of the analysis rests on the demonstration of the permutations and transformations in the symbolic materials themselves. Often it seems as if the participants are thought to undergo ritual transformations automatically upon being exposed to the symbolic meanings of the ritual as they unfold (cf. Kapferer 1979); thus, understanding how ritual symbols are effective is simply a matter of understanding the logic of thought that underlies them.

Many anthropologists have been aware of the limitations of this emphasis on the logico-meaningful, discursive aspects of ritual meaning. They have called attention to the nondiscursive aspects of ritual, emphasizing that rituals gain their effectiveness by being performed. It is through participation in ritual singing and dancing, or through viewing dramatic presentations of sacra, emblems and masks, or through being subjected to painful ordeals that participants come to see symbolic representations as having a force of their own. Vivid ethnographic accounts of exotic rituals make this intuitively apparent. However, the means by which the performance accomplishes this, beyond providing dramatic or emphatic presentation of ritual symbols and provoking strong emotional arousal, is rarely examined. The problem is not to recognize the importance of nondiscursive elements for the efficacy of ritual but to understand exactly how they work.

In this essay, I explore the problem and develop the idea that rituals and their symbols are effective less because they communicate meanings (though that is also important) than because in performances, meanings are reinnovated in social interaction. The participants are engaged with the symbols in the mutual creation of a performance reality, rather than informed by them as knowers. To examine this process we return to the Kaluli séance.

\section{The Kaluli Setting}

The Kaluli people live in about twenty longhouse communities scattered throughout the tropical forest on the Great Papuan Plateau just 
north of Mount Bosavi in the Southern Highlands Province of Papua New Guinea. Kaluli believe the world has a visible aspect, which is the context of everyday life, and an invisible side (largely coextensive with the everyday, but hidden from it), which is the abode of the spirits and the dead. The inhabitants of each side "show through" to some extent into the world of the other. Spirits appear to human beings as certain kinds of birds and animals (Schieffelin 1976; Feld 1982), and every human person has an invisible aspect that appears to the spirits as a wild pig or a cassowary.

Among the population of twelve hundred or so Kaluli people in the early 1970s, there were about fifteen spirit mediums. A medium is a man who has married a spirit woman in a dream or vision experience, often associated with a severe illness. Thereafter, he is capable of leaving his body in séance and traveling in the invisible spirit side of reality. At the same time, spirit people from the invisible may enter his body and converse with the audience gathered around.

Kaluli call séances for a variety of reasons including general entertainment, but, most commonly, they ask a medium to journey to the invisible in order to cure illness or to find lost pigs. One of the principal causes of illness from the Kaluli point of view is an invisible attack on the victim's body by a witch (sei). A sei is a living man or woman who has an evil aspect in the heart. This evil thing creeps out of the sei's body while he or she is asleep, and, assuming the form of its host in the invisible, attacks the invisible aspect of the victim's body, dismembering it and carrying off the pieces to hide for later consumption. The victim comes down with a severe illness whose symptoms correspond to the parts of his body which have been been (invisibly) injured. Thus, a person whose legs have been cut off cannot walk; a person whose head has been removed is delirious, a person whose heart has been cut out dies. It is the job of the medium and his spirit helpers to seek through the invisible and locate the patient's missing (invisible) body parts and stick them back on his or her body.

\section{The Séance Performance}

When someone becomes ill, his or her relatives will often seek out a medium (a:s tih'nan kalu, lit., goes down to the spirits man) and ask him to go into the invisible to see what is the matter. A séance always takes place at night and has a characteristic form. The 
medium lies on his back on a sleeping platform in the men's section of the longhouse, and the men and youths of the community gather about him seated on the floor. These men are called the kegel, which has the meaning more of "chorus" than of "audience." They form the core of those who actively participate in responding to the performance. The women, mainly onlookers, lean over the nearby partitions of the women's section or sit on the floor at some distance behind the men.

When all is ready, the fires of the longhouse are banked to provide almost complete darkness. After a while, there is a long hissing breath from the medium indicating his soul is leaving his body. That is followed by gasping sounds and bird calls (Kaluli believe spirits take the forms of birds) as the first spirit comes up and softly begins to sing. The song, invariably about the hills and streams near where the spirit lives, is nostalgic and moving. The kegel, chorusing the spirit, are drawn into the same mood. When the song ends, the spirit identifies itself, and the people ask him to go and take a look at the sick person and see what is the matter. The spirit child then departs and searches the spirit realm to see if the patient's body from the invisible side has been injured (invisibly) by a sei. If it has, the spirit child must locate the dismembered portions of the body which the sei has hidden and stick them back on the body again. If he is successful in this, the patient will recover.

In the meantime, while the medium and his spirit child are off on their (invisible) errands of healing, other spirit people come up through the medium's body to sing and provide the people at the séance a chance to talk with their dead, or with other invisible personalities of the locality, and to enjoy themselves. Séances often become quite engrossing performances. The mood ranges from deeply affecting as people weep while talking with their dead, to fearsome and thrilling as fierce and belligerent spirits come up with growling voices, smacking lips and thumping and banging on the sleeping platform. Or the séance may be hilariously salacious as when an unmarried spirit woman and the young men of the longhouse lewdly tease and provoke each other. In this context spirit people of the locality become well-known and even beloved personalities, and Kaluli develop a closer general relationship between themselves and the invisible side of their world.

All during the performance the kegel sitting around the medium 
maintain an active participation by chorusing the singing, asking questions and engaging in conversation with the spirits-and in commenting and speculating among themselves about the meaning and quality of the performance itself. Often this discussion is led by one or two self-appointed shills who, while not in collusion with the medium, are familiar with his style and know how to anticipate what he is likely to do next. They often give a running commentary and interpretation of the performance as it goes along.

During the course of the night, the medium's spirit child continues his attempts to help the patient. I have examined this healing process in the séance through a meaning-centered analysis (Schieffelin 1976, 1977). I argued that, in everyday life, Kaluli tend to interpret and deal with many different kinds of situations as though they were situations of opposition or confrontation that could be solved by reciprocity. Illness is assimilated to this model. That is, illness is interpreted (in séance) in terms of the opposition between the patient and the sei who has stolen part of his body. The opposition is mediated and resolved in a reciprocity-like transaction performed by the medium's spirit child when he finds and returns the missing parts of the patient's body that have been dismembered by the sei. The basic thrust of the argument, following Lévi-Strauss (1967), was that by assimilating the patient's suffering to a metaphoric version of a widely significant cultural scenario of resolution, the séance provided a means to make sense of, and to order and resolve, his problematic bodily experience. Subsequent research in Bosavi has shown that this cannot be what happens, at least not in the way outlined by most meaningcentered arguments of this sort. I will return to this point later on. In any case, the séance usually continues well into the middle of the night until all of the various spirit tasks have been successfully (or unsuccessfully) accomplished. Then the medium returns to his body and sits up.

This brief overview outlines the basic events in a Kaluli curing séance. Understanding what is happening here, however, is more than a matter of showing that the séance provides a logically and symbolically plausible resolution for a problematic situation. It is also necessary to show why Kaluli people accept what they see in the séance as a convincing, even compelling, reality. This is not so much a question of what Kaluli believe is happening as it is of how what they believe is brought to life and galvanizes social reality. 


\section{Playing the Urgency of the Social Situation}

The compelling quality of the séance begins long before the performance itself begins, in the depth of the social concern out of which it arises. Although people sometimes request a séance just for the amusement of talking to the spirits, they call most of them to deal with some problematic circumstance. The people who gather about the medium in the longhouse are not only excited about the prospect of the performance; they are worried or angry and hope to obtain some answers. This anxiety and expectancy charges the atmosphere with a certain tension before the séance begins, and it is this tension that the séance must pick up and deal with, develop or resolve if it is to make a difference-and in the process become real. Some mediums have a keen sense of this preliminary urgency and play on it to create the proper opening mood. Walia of Anasi, one well-known medium, was a master at building the tension of community worry and expectation to an agonizing pitch. When asked to go out to the spirits, he would be diffident, complaining that he did not feel well, or that the kids in the longhouse were too noisy and would disrupt the séance. The people who wanted the séance would plead with him, offer him food, promise to monitor the children, and clear off their sleeping platforms for him to lie on. Walia would continue to grump reluctantly and threaten to leave right up to the point where he lay down for the séance, by which time audience tension was highly keyed and people were anxious to begin the performance.

\section{The Séance Setting}

When the medium lies down on one of the sleeping platforms to begin the séance, there is an atmosphere of hushed excitement. The kegel and other onlookers settle themselves in the darkness to await the arrival of the first spirit. Although this situation is reminiscent of a Western theater audience quieting down before the curtain rises, the resemblance is superficial. The cultural assumptions that shape the internal structure of the performance space for the séance are very different from those which inform a proscenium stage. As a result, the implications for the relationships between the audience, actor, and characters are also very different. The stage in a proscenium theater defines a special space to house an imaginative reality, which excludes 
the audience, but is kept in place by their suspension of disbelief: that is, the audience may accept for the performance that they are in the presence of the court of Richard II, but not that they are part of it. Indeed, they cannot be part of it for the performance to retain its integrity. A member of the audience who mounts the stage because he believes what he sees there is real finds himself among actors, not kings, disrupts the imaginative space, and spoils the show.

For the Kaluli séance, the situation is reversed. In the seance the imaginative space of the proscenium stage is exchanged for the liminal realm of the medium's trance; the actor (that is, the medium) is excluded from the performance (since his soul has left his body), and the characters (the spirits) then enter reality. This is accomplished by a double transfer across the line between the visible and invisible sides. The medium ascends to the invisible while the spirits descend to the human plane. Thus theater becomes reality: where spirits who are birds converse with men in human voices. It also means that the interactions with the characters (spirits) have real consequences. The thrill of fear at the appearance of a fierce and belligerent spirit is not vicarious. If the spirit becomes angry and causes the medium's body to thrash about on the sleeping platform, the audience may flee the longhouse.

As the séance commences, however, the performance space-where "the characters enter reality"-is not simply taken for granted. It must be continually re-created during the course of the performance. This means that the medium must commit the audience to the task of participating in its construction, and this is accomplished in large part through the spirit's songs.

\section{The Spirit Songs}

The spirits come up one by one, and each sings a song that is chorused by the audience. Each song may be followed immediately by another song, or by a period of conversation between the spirit and the audience.

Although mediums ${ }^{1}$ do not speak about the artistic skills required to perform a good séance (indeed they would deny they were even present), it is evident to an observer that certain requirements have to be fulfilled if the structure of the séance is to be sustained and the performance made to work. One of the most important is to control 
the focus of everyone's attention and to maintain the right unity of mood throughout the performance. The medium accomplishes this mainly through adept management of the songs. Most of the power and energy of the séance come not from conversations with the spirits but from the songs. It is through the people's participation in chorusing the songs that their divided attention is brought together and focused, and it is through the content of the songs that the mood of pathos and nostalgia appropriate to speaking with the spirits can be evoked and intensified. A successful trance medium has to have the ability to compose, during performance, in trance, as many as thirty new songs, each one with a different set of underlying implications. For our purposes, it will be enough to summarize one or two points to provide understanding of how they can be used as powerful rhetorical devices.

Superficially, the songs seem simple enough. They refer to various named places-hills, streams, garden spots, old longhouse sites, and the like in the local forest region. Often the places are named in such a way that they mark out a definite path $(t o k)$ through the local forest region, naming landmarks and singing the calls of birds as though one were passing through there. The localities named are familiar to many members of the audience and have a special poignancy for those who have spent parts of their lives there and for whom they represent the contexts of social relationships and events of times past, activities shared with beloved friends and others now dead or gone away. The poignancy is enhanced as the song frames its passage through the various localities in poetic images evoking nostalgia, longing and loneliness.

In the séance the spirit frequently sings about the places he has lived in that represent his relationship with people in the audience. A spirit of the dead may sing of the localities it shared with members of the community when alive, or, as in the case cited at the beginning of this essay, trace a path associated with the events of his or her death. Spirits of the locality (who have never been alive) may sing of the areas in which they live, or of places along the path they took coming to the séance. If the spirit was off on an errand of healing, it may sing of the places it has traveled in carrying it out.

Thus, the places sung by the spirits are loaded with implications and messages for the listeners. A given locality may mean different things to different individuals according to their experience and social relationships there - or they may imply several different things to the same person. The ambiguities of who (which spirit) is actually singing, 
which locality or what events the song refers to are only slowly sorted out as the song proceeds, and the track it unravels becomes clear. The people present at the séance eagerly try to figure all this out as they participate in the chorus, or simply listen. As the song continues, one can hear exclamations of "There's Dogon hill! that must be my mother's brother, old so-and-so. He used to garden there." "No, no, he also sang the Galinti pool; it's somebody further downstream." Tension mounts while the people search their minds to figure out the riddle of the singer until the song ends and the spirit announces itself. If the song has built up the right mood, the spirit's living relatives break down at this point and weep. Alternatively, if the spirit that comes up is a local place spirit, not one of the dead, there will be exclamations of welcome. Often people do not know whether they will be weeping until the very last minute.

In a still deeper strategy of the same kind, the song may not contain any place names at all; it may simply mention trees and river pools and sago stands as though they were passed on a track without any indication of where they actually might be (Feld 1982: 152). Those present are led to search their memories for an area that would match, and the tension and speculation mount until the mention of one or two place names near the end of the songs suddenly precipitates recognition of the locality, and, at the same time usually, the identity of the spirit-followed perhaps by a flood of weeping. These mystifications and ambiguities within the song tantalize members of the audience and force them to turn reflectively inward by invoking the places that they know and love.

This focusing of attention in nostalgia and pathos is further intensified and given momentum by the strategies of performance by which the medium puts a series of songs across. To some degree these strategies seem to be a matter of personal style. Two contrasting examples will illustrate this point.

Aiba of Kokonesi was a socially dynamic man of considerable presence. Intense and somewhat intrusive, he had a disconcerting habit of suddenly being present when least expected. ${ }^{2} \mathrm{He}$ had an extraordinary knowledge of the forest geography over most of the Kaluli region; nearly every village knew him. In my experience he was an opportunistic, persistent, and manipulative individual in everyday life.

In séance, Aiba projected his spirit songs in a strongly focused and carefully constructed manner. His songs were less stylized and textually and musically more diverse than those of other mediums. $\mathrm{He}$ 
seemed to create a personal rhythm aimed at centering the séance participants' attention on him and what he was doing, drawing them onto his ground of performance where he could control them and make them, in effect, dance to his tune. Once those at the séance were hooked, they were driven by his energy. His carefully pointed songs were frequently deeply affecting and often moved some people to tears. However, because the energy of his performance derived mainly from himself, there was a tendency for its intensity to collapse between songs unless the level of tension was sustained by someone weeping.

By contrast, another medium, Walia of Anasi, was a rather marginal character. Scruffy, wheedling, and unreliable, he was a responder to rather than an initiator of any significant social action. Yet he was an incredible trance performer. Walia, in séance, did not focus people's attention on himself; he seemed more oriented to orchestrating group synchrony. His songs, particularly at the beginning of a séance, tended to be highly stylized and predictable (Feld, personal communication), using the same or similar melodic patterns and similar poetic images and song forms over and over again. Walia was finely attuned to his audience's response and the predictable regularity of his songs seemed aimed at getting his chorus to sing together well, to synchronize themselves to the same rhythm. Once they were unified, he did not manipulate them; he acted more as an orchestrator and catalyst to group process. It usually took Walia a longer time than Aiba to build the right momentum, but once he did, it tended to sweep up the greater part of those present and carry them forward with an enormous force that maintained momentum through spirit conversations to the next song.

The songs, then, provide several dimensions to the performance. The singing of them, with the kegel chorusing the spirit, provides unity of purpose, concentration, and rhythm to those present at the séance, building a compelling musical momentum that supplies the sense of energy and forward motion to the performance. The singing of lands and waters presents the listeners with an intriguing but ambiguous message which they strive to interpret. Amid mounting suspense and expectancy, they try to figure out whom they are singing with. Finally, when the song is completed, they are so steeped in nostalgia for their lands and longing for their dead that they are in the right mood of emotional expectancy to converse with the spirits. 


\section{The Spirits}

The spirits are the central characters in the séance and provide both its edifying and its entertaining aspects. As the audience engages in conversation with them, they become living personalities. At the same time, the work of the séance gets done. In the darkness, the presence of a spirit is marked by a change in the medium's voice quality. Generally speaking, spirit voices sound rather pinched and smaller than the medium's normal voice and speak in a somewhat higher register. Some mediums used the same spirit voice for most of the spirit manifestations., but the best, or at least the most dramatic performers had a different voice quality for every different spirit.

Experienced mediums could present a cast of twenty or more spirit characters, in addition to the spirits of the dead. Some of the spirits of a medium's locality had long-term traditional relationships with the local community, had appeared through a series of mediums over a period of years, and were well known or even beloved by those present in the audience. (I was able to trace the history of the relationship between one such spirit and a nearby community over eighty years, back to the turn of the last century (Schieffelin 1977)). Other spirits appeared only through a particular medium and might not make appearances through other mediums after his death. As with the dead, these place spirits were associated with particular localities, and séance fans could often guess by the songs which one was coming up. The Kaluli distinguish four types of spirit that can appear through a medium. Spirits of the dead generally precipitate a great deal of weeping if their relatives are present. Conversation with them generally concerns such things as where the spirit is now residing, and what has happened in the way of family news since his or her death. In former times there was frequently some discussion to determine the identity of the witch responsible for the death.

Most of the spirits who come up on a medium, however, are place spirits, spirits associated with a locality. These spirits often have distinctive personalities and reputations among séance-goers for their different indiosyncrasies and abilities. One of Walia's favorite spirit personalities (which he had inherited from his mother's brother, who was also a medium) was a spirit named Kidel, who lived at a place called Bolekini. Kidel had a deep, friendly voice and was known to be fond of tobacco. He would frequently ask someone to pass a smoking 


\section{Edward L. Schieffelin}

tube in his (the medium's) direction during the seance. When he came up upon Walia, he projected the character of a tough, far-traveled person, and was relied upon to predict when the government patrols would visit the area. An older spirit, he would sometimes talk about how his children were growing or comment on recent changes in the spirit world.

Another favorite, particularly with the bachelors, was a young unmarried woman named Daluami. She was rather forward and provocative and spoke with a coy, falsetto voice; her conversations with the young bachelors of the community quickly became lewd and ribald repartee, accompanied by howls of laughter throughout the longhouse. $^{3}$

These spirits of the ground are usually the ones to perform the most dramatic séance tricks. For example, in one famous performance, a spirit invited the people attending to light the medium briefly so they could see him. When they did so, they saw a hornbill's beak (from the spirit's bird manifestation) sticking out of the medium's mouth. Another spirit asked to borrow a shell necklace in order to dance in a Gisaro ceremony in the spirit world. A necklace was placed on the medium's chest and disappeared. Sometime later, at another séance, the spirit returned the necklace stained with the fragrant vegetable resins used to annoint a ceremonial dancer.

A third type of spirit is called a Newelesu. Characterized as a weedy little man with an oversized head and an enormous penis, he lives in the top of small wani palms (a decidedly inferior dwelling compared to the gigantic buttressed trees normally inhabited by spirits). A Newelesu is a clownish, trickster-like figure, always horny and mischievous. He comes up on a medium with a squeaky voice and a shrill, highpitched laugh and usually demands to be given a woman. Hilarious conversation follows. The Newelesu is known to be a witch on the spirit side, responsible for the demise of animals occasionally found dead and decaying in the forest. Men in the audience frequently ask him to "ripen" a wild pig or cassowary so that it will fall prey to their traps or hunting arrows. Newelesu has an angry streak in him and sometimes sends the medium back to his body, terminating the séance if he is teased by the people too much.

Finally, there are fierce spirits known as kalu hungo:, or "dangerous, forbidden men." These spirits are known to be rough and shorttempered. They usually appear in séance smacking their lips hungrily or uttering battle cries and speaking in deep spooky voices. Kalu 
hungo: are known to strike people down if they get angry, and it is they who tend to frighten the audience out of the longhouse. Conversations with kalu hungo: are generally excessively polite and conciliatory, and Kaluli appeared to enjoy the thrill of danger that these spirits provided.

In the course of a séance (and depending on the medium), a wide range of different spirit characters would come up. Some would only reveal their names before departing. Others would stay to converse, argue with or tease the people at the séance for a considerable time. It is the conversations with the spirits, especially given their lively variety that break the flow and accumulated intensity of the songs and give Kaluli séances their episodic character. From time to time during the night, the medium's spirit child returns to report on his progress on helping the patient on whose behalf the séance was called. But apart from this, there is usually little apparent continuity between one spirit conversation and another. Sometimes, however, a medium will link the succession of spirit conversations with an underlying dramaturgical strategy that sets up the audience and then pulls a switch on it, leaving everyone surprised and disconcerted. In one séance, for example, Daluame, the provocative, unmarried female spirit, came up and engaged the young men of the community in an extended racy repartee. There was much hilarity, and an atmosphere of randy excitement developed. After she departed, another female came up, but this one was of demure and timid character. The young men of the audience were still full of ribaldry from their conversation with Daluame and teased the second spirit mercilessly until she departed in flustered embarrassment. The performance then turned the tables on them: a cooing, high-pitched voice came up, heralding the appearance of a third woman. As the young men prepared to launch into further lascivious provocations, the spirit made several remarks so outrageously salacious that the bachelors, despite their raucous mood, were taken aback. In the bewildered silence that followed, a shrill gale of familiar silly giggles revealed that the spirit was not a woman but a Newelesu, trickster.

These conversations with the spirits in the darkness of the longhouse create a lively scene. The wails of grieving relatives, the matching of wits in outrageous repartee, the thrill of danger from fierce kalu hungo: are all deeply engrossing and enjoyable interactions quite apart from the particular purposes for which the séance was called. If at times these conversations strike an outsider as having the quality of play, it 


\section{Edward L. Schieffelin}

is not like the play of make-believe; it is like the play of joking relations, of playing with fire: playing in an arena of forces that can have dangerous consequences.

If people's attention begins to falter during the spirit conversations, new songs will reestablish the mood, rebuild momentum and intensity, and maintain continuity.

\section{The "Audience"}

The kegel gathered immediately around the medium forms the principal core of the séance participation. They do the chorusing of the spirit songs and generate most of the joking and banter. Other, usually older, men sit as spectators at the periphery of this group or in other parts of the men's section, talking among themselves, occasionally joining the singing, but always alert to what is going on. Women too mainly observe, but make their presence felt through comments and exclamations at the performance or occasionally prompting a question to the spirits.

It should be obvious by now that the people gathered to attend the séance are an integral part of the performance, and that the term "audience," with its implication of passive attention, is probably not the right word for this group. I have used it, sparingly, to refer to both active participants (kegel) and more passive onlookers. The reality of the spirit world as it is embodied in the séance is not the result of the performance of the medium alone; it is created in the interaction between the people present and the spirits. If the people are unresponsive, or unwilling to participate, the energy drains away, and the séance collapses and comes to an end.

While the medium depends on the people's response to keep the performance going, he is also subject to their judgment. Members of séance audiences are sophisticated. Séance performances form a genre, and most of those present have seen other séances before and know how to evaluate them. People not only sing along and converse with the spirits; they also make comments aloud among themselves about the spirits' character and style, comparing the way they seemed in other performances or how they appeared with another medium. Thus, information about performance adequacy and character roles is made available during the performance itself where it may be considered by others present or act as feedback to the medium, if he can 
hear them while in trance. During the performance people may make exclamations of praise or approval for a particularly well-done song or enjoyable conversation. They have also been known to denounce the séance or walk out on it in disgust if they believe that the spirits do not know what they are talking about or that they are being tricked. The audience thus becomes the arbiter of the authenticity of the spirit séance, and at least as much as the medium, the guardian of the rigor of its tradition.

\section{The Ostensible Work of the Séance}

\section{Dialogic Modes of Constructing Reality}

It is in the midst of deep audience engagement that the work of the séance gets done. The question is: what does it actually accomplish and how? From the Kaluli point of view the two most important tasks of séances are the curing of illness and the recovery of runaway pigs. Nevertheless, the actual proportion of séance performance time devoted to such matters varies a great deal, sometimes being a rather insignificant and perfunctory part of the performance, and sometimes being lengthy and dramatic. In regard to curing, I have already discussed the symbolic process in the séance curing scenario where the illness is construed as a loss (on the invisible plane) and is then resolved through a symbolic analogue of social reciprocity carried out invisibly by the medium and the spirits. (See also Schieffelin 1976: chap. 5.) It seems reasonable to argue, following the outlines of Lévi-Strauss (1967), that the powerful symbolic process embodied in the curing scenario, delivered to a deeply engaged audience, might actually have the effect of transforming the experience of the patient. However, unless we postulate the operation of paranormal effects, this cannot be the case because usually the patient is not present at the séance. In addition, Kaluli believe that patients must be asleep for the medium to have proper access to them from the invisible side. This means that despite the powerful symbolic scenario embodied in the curing process, it cannot affect the patient in any normally understood way. Nevertheless, Kaluli laymen and mediums alike insist that the reputation of a medium rests on the success of his cures.

In the séance context, if the power of the curing sequence cannot affect the illness process of the patient, it can perhaps shape the 


\section{Edward L. Schieffelin}

expectations of the patient's community about the outcome. That is, during the performance, the medium may form an assessment (even just a guess) about the patient's condition and gear the level of success of his invisible curing efforts to correspond with his notion of the most probable outcome; if he does not think the patient will recover, he will have difficulty in locating the dismembered legs taken by the sei or performing other acts of curing. In this way he will be preparing the people of the community for what to expect-making a prediction in the guise of an attempt to cure. Be this as it may-and the evidence is not very clear on the matter-the curing scenario can be seen as a very important part of another aspect of the séance, namely, that aspect dealing with witchcraft (to which we shall return). Some of what the medium is doing in the cure will be clarified by turning to a more minor matter: the finding of runaway pigs.

In listening to mediums (or rather, spirits) discuss lost pigs with the audience, an observer notices that they show great subtlety in negotiating information to construct an appropriate response. During one séance I observed, the medium's spirit child was sent to locate a missing pig described as a female with cropped ears and a white patch on the chest. Later returning to the séance, the spirit declared: "I saw the pig but I do not know the name of the ground." He went on to describe a place where a small brook ran into a larger creek with a particular kind of sago palm nearby. I recorded the discussion in my fieldnotes:

"There is also a Wolu (river) banana garden nearby," he said. The (audience) said: "No, it is the Gulu (river) you are talking about" (The particular type of sago at the confluence of two waters was the clincher here for recognizing the area since there was a stand of that kind of sago at the confluence of the Gulu and Gudep streams.) The audience then figured out among themselves that the banana garden referred to was probably the one at Mosogosaso. The spirit then described a old fish-dam diversion ditch and an abandoned garden. The audience agreed in discussion that this described the general area around the mouth of the Gudep stream. One man prematurely identified the area as a place called Gwabidano which is nearby, but was overruled by others in favor of the Gudep again when the spirit mentioned a pandanus garden which they identified as belonging to one of themselves. By now even the writer could recognize the area from the description. That was where the pig was supposed to be. Only one man remained skeptical. He believed the spirit must have the wrong pig, because he thought the 
one they were looking for should have been at another place closer to the Wolu river.

On the following day when the pig owner visited the place designated by the spirit, he did in fact find a female pig with cropped ears and a white patch on its chest. But it was the wrong pig. This pig was a little one; the one he was looking for was much larger. He returned to the longhouse disgruntled.

In the séance, the spirit's information comes across as markedly ambiguous. There are dozens of places in the tropical forest that would fit his initial description. However, by "not knowing the name" of the ground, he avoided pinpointing a specific location. ${ }^{4}$ This allowed the people present to figure out the location by drawing implicitly on their knowledge of local lands and the behavior of pigs. The area the people actually considered was restricted to a region on the Gudeb stream not too far from the lost pig's normal range. Thus, they took issue almost at once with the spirit's suggestion that the pig was somewhere near the Wolu river. From then on, the various details suggested by the spirit were sufficient for the audience to piece together a picture and reach a consensus about where the pig was located. When the location of the pig was finally determined, the séance participants doubtless felt that they had received it on spiritual authority; to a Western observer, it appeared that they had constructed most of it themselves.

This event in which the spirit communicates the whereabouts of a lost pig epitomizes the process of the social construction of reality in the séance. The spirit imparts information at once clear and ambiguous (a definite place described, but the location not named), and the audience attempts to figure out where it is. The effect is reminiscent of the speculative mental search people employ with each new song to figure out which spirit is singing. The deciphering of the spirit's message is a cooperative construction of reality in the guise of a search and clarification of hidden meaning; that is, as the people search for clarification of the spirit's message, they create the meaning they discover.

\section{Dramaturgical Means of Constructing Reality}

Not all of the séance reality derives from the dialogic interaction between the séance-goers and the spirits. Directly dramaturgical ele- 
ments incorporated in or utilized by the performance shape the significance of the dialogue and serve as major means by which séance and everyday realities overflow and spill into each other. This is particularly clear in the way the séance articulates the dark side of Kaluli life, witchcraft and death. Witches (seis) are a frequent topic of séance conversation. At times when there is sickness in the area, discussion of seis, their habits and whereabouts may dominate conversations in séance. Fear and dismay over their activities are aroused through lengthy and often harrowing discussions between the audience and the spirits concerning efforts to locate the (invisible) dismembered pieces of the victim's sei-torn body. At such times, the ambiance of anger and anxiety coupled with a jumpy alertness to small noises of the night can generate a spooky awareness of evil presence that may prickle the scalp of even an observer.

In the middle of one such séance I attended, while the participants were deeply involved in chorusing the song, there was a peculiar noise outside the longhouse. The spirit voice suddenly fell silent, and the chorus was left stranded at the edge of response. In the ensuing moments of consternation in the darkness of the longhouse, everyone was poised to listen. The strange noise and the sudden disappearance of the spirit voice meant a sei was creeping just outside. There could hardly be a more jarring interruption of the performance than this. Through the abrupt silence, the thrill of fear, and the sudden alertness of the audience, the presence of the invisible sei-creature was rendered virtually palpable. Its presence was realized not by anything that was said but through the dramatic moment it evoked. Although the context was set up and interpreted through cultural assumptions and symbolic understandings, it took an act of performance to precipitate the sei sensually into reality. The drama did not end there: the medium was paralyzed, his soul blocked from returning from the spirit world by the presence of the sei. It took twenty minutes of concerned activity, including prayers to Jesus by Christian converts and the efforts of another medium who called down the mouth of his stricken colleague to his own helpers in the spirit world, before the spirit path was cleared of the sei's presence and the seance could continue.

In this kind of highly charged context, discussions of seis take on a dismaying immediacy. The spirits, again, rarely give the names of the seis they see, but they provide (as for the songs and the pigs) enough information for the members of the audience to construct their own conclusions. Once they have constructed them, they are committed 
to them. In traditional times, if the sei was responsible for someone's death, the result might have been a retaliatory murder.

The reality of seis, marked by the interruption of the séance (or, at other times, by mysterious whistles in the night forest) provides the context in which the instrumental activities of sticking (invisible) dismembered limbs back on bodies appear as urgent, meaningful, and effective behavior. It makes sense because the séance does not simply discuss seis, it presents them concretely as real. In this sense theatre becomes reality: the characters are not on the stage, they are out in the world.

\section{Séance Performance and the Construction of Cosmological Context}

While séances construct realities on the ground, they also articulate everyday realities with cosmological ones from above. Séances are, of course, understood by Kaluli in terms of cultural beliefs and assumptions about the nature of the world and the relationship between spirits and human beings. It is customary in anthropological analysis to approach the understanding of cultural performances by grasping them within such a context of the larger system of belief; that was our strategy in outlining Kaluli spirit beliefs at the beginning of this paper. However, a case could also be made for pursuing the matter the other way around. Kaluli spirit beliefs do not form a thoroughgoing and consistent system. Systematic inquiry reveals that beyond a basic set of common understandings (such as outlined at the beginning of the discussion of séance), there is a great deal of variation in the amount that people know about the invisible realm, and many lacunae and inconsistencies in the content of this knowledge. The piecemeal and miscellaneous nature of individuals' knowledge of the invisible reflects to some extent the piecemeal and miscellaneous nature of the contexts in which they acquire it. There is little formal instruction in the lore. What one learns is picked up informally in everyday context from casual remarks and conversations, from accounts told by knowledgeable people about spirit or witchcraft-related events, from the atmosphere of alertness to peculiar sounds of the forest, and from attending and discussing seances. Kaluli laymen are generally not aware of the variation and inconsistency in their knowledge of the invisible. When it is pointed out, they are as puzzled by it as the ethnographer; usually they suggest 


\section{Edward L. Schieffelin}

that he go and talk with a medium. Mediums are the final authorities on the invisible, not because they are in possession of greater traditional knowledge, but because they have been to the spirit side and seen it for themselves.

Medium's accounts of the invisible are visually detailed and systematic, lending credence to their claim to having actually been there during trance. However, while a common set of cultural themes seems to underly their accounts, the various mediums' versions of the invisible differ from each other considerably (as well as from the laymen's). Mediums, however, do not discuss their trance experiences much among themselves and are largely unaware of the degree to which they differ. Moreover, their differences do not effect the way they perform their séances and are rarely significant in the details of performance content. The inconsistencies of the system rarely surface and, thus, do not pose difficulties for the Kaluli, only for the ethnographer.

One interesting consequence of this situation is the difficulty it poses for conventional ways of talking about a "belief system." A common approach would be to look for common themes and cultural assumptions that underlie the variant accounts, but to give an account of this system by reducing it to its common denominators would clearly distort it. Instead, the best way to preserve its ethnographic integrity is to look at it in terms of the way that it is socially constructed: that is, as a system which consists in the continuing interaction between what people already know of spirits from oral tradition, everyday conversation, and remembered (or reported) past séances, and whatever new experience comes up in the present séance performance. What people know serves as a general background and constraint on what they will accept in a séance performance, but the performance is the presence of the spirits themselves and provides continuing information to the audience on the state of their relations with them. This material, which may contain innovative information, is then reassimilated by the people present to their stock of knowledge. It may be communicated to others who did not attend that particular séance, held as information for future use, or conveniently forgotten. Mediums themselves sometimes contribute further by describing to others in their longhouse some of the things they have seen in their trance journeys that did not emerge in séance. In this way, knowledge of the spirit world is kept, within certain general limits, continually in flux, being constantly generated and renewed and irregularly distributed throughout the 
social field-where it forms part of the context for understanding new séance performances and spirit-related events. Heterogeneity is automatically part of the system no less than its underlying shared cultural assumptions. In this sense, it is more the performance of séances that accounts for the nature and content of Kaluli belief than the other way around. The accumulated knowledge of the spirit word clearly takes second place to the presence of the spirits themselves in performance, and the spirit world, like the identities of the singers of the songs, or the locations of lost pigs, seems at once familiar and just out of reach.

It is when Kaluli reach out to the spirits in séance that they becomes most clearly aware of the larger, cosmological scheme of things that the spirits represent. It is in the séance that they are most likely to experience the direct articulation of that order in their own life space. This articulation is, of course, implicit in the conversations with the spirits and the participation in chorusing the songs. But to take a more explicit example, it is in séance conversations that people enter into relationships with the spirits that individualize, consolidate and legitimize their relationship to the land. One informant told me the story of a taboo area near his longhouse where no one was permitted to hunt or fish. Years before, he explained, a fierce kalu hungo: spirit had come up in a séance and declared that he was the owner of the area: "Don't cut the trees or the arrow cane there," he had told them, "or I will cut off your clan." Commenting on the story, my informant remarked: "He made the arrow cane like our soul." This meant, in one sense, simply: "We die if we cut it." But on another level what looks simply like a lethal threat is regarded by the Kaluli as more like a covenant. The taboo is a sort of mutual agreement between the community and the spirit and, rather than distancing the two, it brings the people into closer and more familiar touch with the forces that animate their locality.

\section{Conclusion}

While symbolic analyses would tend to look at the Kaluli séance as a text or structure of meanings, I have tried to move beyond this to see it as an emergent social construction. The reality evoked in the performance does not emerge directly from its following a coherent ritual structure (though it does follow one) but rather, within that, 


\section{Edward L. Schieffelin}

from the process of dialogic interaction between the medium and the participants. What renders the performance compelling is not primarily the meanings embodied in symbolic materials themselves (the spirit characters and their pronouncements) but the way the symbolic material emerges within the interaction. Starting with the people's anxiety and expectation over problems in everyday life, the séance develops its force by weaving over and around these concerns its own theatrically generated tensions and ambiguities. The songs tease and provoke the listeners, drawing them into the interaction. The séance makes sense not so much by providing information as by getting the audience into motion, bearing down on curiosity and nostalgia to force out dramatic and emotional as much as cognitive significance. It entices, arouses, and intrigues so that the participant constantly strives to get a hold of something that always seems just out of his grasp. The performance is gripping not because of the vivid display of symbolic materials but because the symbolic material is incomplete. Reality and conviction reside not in the spirit's message but in the tension produced when something important he says seems clear, while, in fact, it is still ambiguous. It is this experience of inconclusiveness and imbalance that gives the people little choice but to make their own moves of creative imagination if they are to make sense of the performance and arrive at a meaningful account of what is happening. In so doing, however, they complete the construction of its reality.

In this way, Kaluli people contact the fundamental symbolic understandings of their culture and arrive at solutions to their problems, not in a cognitive or intellectual way so much as in a participant one, whose cognitive shape is not necessarily very well worked out for a given individual, but which is assumed to make sense because the realities it represents are so vivid. Once this (séance) reality is constructed, it may spill over into everyday life so that it not only reflects Kaluli cultural situations, but also defines, constructs and realizes them. In the end, the performance, in effect, becomes life, no less than life is reflected in the performance; the vehicle for constructing social reality and personal conviction appears to be just as much drama as rational thought.

It is evident that it is impossible to separate the dramatic aspects of ritual symbols from their meanings if we want to know their significance or why they are compelling in the emerging performance. This is not just a matter of presentation: many things are cognitively accepted in performance precisely because they are dramatic, im- 
pressive, or mysterious rather than because their rational significance is understood, provided, of course, it does not stray too far outside the limits of cultural common sense. The presence and reality of the sei was made palpable by the jarring interruption of the seance, but the interruption itself would have had no meaning if it were not for the existence, for the Kaluli, of the sei.

It is the socially emergent dimension of performance, constructed through the interaction of the performers and participants but not reducible to them, that constitutes the reality in which the actual work of the séance gets done. This emergent dimension stands beyond the text or structure of the performance itself (while at the same time embodying it), so that the séance confronts the participants as an event in which they are involved and which can have consequences for them and their particular situation. This being so, the work of a performance, what it does and how it does it, can never be discovered only by examining the text, or the script, or the symbolic meanings embodied in the ritual alone. It must be sought further in the emerging relation between the performer and other participants (and the participants among themselves) while the performance is in progress.

It is because ritual in performance is a reality apart from its participants that the participants may not all experience the same significance or efficacy from it. Indeed, unless there is some kind of exegetical supervision of both performance and interpretation by guardians of orthodoxy, the performance is bound to mean different things to different people. In the absence of any exegetical canon one might even argue there was no single "correct" or "right" meaning for a ritual at all—or at least not a specific one. In this sense the performance can be seen as an arena in which each participant creates, together with the central performers and other participants, the meaning that the ritual has for him or her. The structure of the ritual, together with its conventionally understood exegesis and intent, will circumscribe the range of that participant's experience within it, but rarely fully determine it, for the participant contributes his own construction to the ritual events. The performance receives its validation socially from the participants when they acknowledge that they have shared in its action and intensity and agree about some aspects of its meaning, whatever else each person may think about it. It follows that the meaning of ritual performances is only partly resident in the symbols and symbolic structures of which they are constructed. In significant part (and particularly in events like the Kaluli séance), the meanings of the symbols 
and of the rite itself are created during the performance, evoked in the participants' imagination in the negotiation between the principal performers and the participants.

This being the case, rituals (certainly Kaluli séances) do not exist in a vacuum of structural scripts and frames. Insofar as they are performed, they have historicity. However much a genre, a conventional, structured, symbolic enactment with a limited range of meanings, the séance is also an event which the participants help construct and to which they contribute that part of the ambiance, action, and final significance that it evokes from them.

\section{Notes}

1. The Kaluli mediums that I knew did not exhibit any unusual or outstanding characteristics as individuals in ordinary life. Quite the contrary. The six mediums that I worked with represented a wide range of personal styles, degrees of extension of social connections, and general social influence. They ranged from one man of considerable influence, who was widely traveled in the region, through less widely connected individuals of more average standing and limited range, to two socially marginal men.

2. This habit was disconcerting to the Kaluli as well as to the ethnographer and may have been part of the reason that in addition to being respected as a medium, he was also feared as a sei.

3 . It is worth remarking that this kind of raucous, lascivious joking and teasing between the young men and spirit women practically never went on between men and women in real life, and certainly never in public. Kaluli would be too embarrassed or afraid to do such a thing. The social repercussions (should relatives of the woman find out) would be serious, since such activity would imply the young man was taking marital/sexual liberties with the woman that were her family's alone to dispose of; hence, he would be acting as if he were "stealing" her (afa di). Because marriage/ sexual activity with a spirit woman is impossible in an everyday context, such sexual joking is harmless fun. It never leads to a spirit marriage that results in a man becoming a medium.

4. I should mention that the medium in this performance was not from the longhouse where the performance was being held and was not himself very familiar with the local grounds.

\section{REFERENCES}

Feld, Steven. 1982. Sound and Sentiment: Birds, Weeping Poetics, and Song in Kaluli Expression. Philadelphia: University of Pennsylvania Press. 
Kapferer, Bruce. 1979a. "Introduction: Ritual Process and the Transformation of Context." Social Analysis 1, 1: 3-19.

. 1979b. "Entertaining Demons: Comedy, Interaction, and Meaning in a Sinhalese Healing Ritual.” Social Analysis 1, 1:108-52.

Lévi-Strauss, Claude. 1967. "The Effectiveness of Symbols." In Lévi-Strauss, Structural Anthropology. New York: Anchor Books, Doubleday.

Schieffelin, Edward. 1976. The Sorrow of the Lonely and the Burning of the Dancers. New York: St. Martins Press.

. 1977. "The Unseen Influence: Tranced Mediums as Historical Innovators." Journal de la Société des Oceanistes 33, 56-57: 169-78.

1980. "Reciprocity and the Construction of Reality on the Papuan Plateau." Man 15, 3: 150-56. 